\title{
Report
}

\section{Challenges and Prospects of Solid Waste Management in Ghana}

\author{
Thomas Samwine ${ }^{1}$, Peng $\mathrm{Wu}^{1,2}$, Lezhong $\mathrm{Xu}^{1,2,{ }^{*}}$, Yaoliang Shen ${ }^{1,2}$, Emmanuel Appiah ${ }^{1}$, \\ Wang Yaoqi ${ }^{1}$ \\ ${ }^{1}$ School of Environmental Science and Engineering, Suzhou University of Science and Technology, Suzhou, China \\ ${ }^{2}$ Jiangsu Collaborative Innovation Center of Technology and Material of Water Treatment, Suzhou, China \\ Email address: \\ dsamthos@gmail.com (T. Samwine),wupengniu@126.com (Peng Wu), kgre505@163.com (Lezhong Xu), \\ ylshen@mail.usts.edu.cn (Yaoliang Shen), emmappia201@yahoo.com (E. Appiah), sheetaone@163.com (Wang Yaoqi) \\ ${ }^{*}$ Corresponding author
}

\section{To cite this article:}

Thomas Samwine, Peng Wu, Lezhong Xu, Yaoliang Shen, Emmanuel Appiah, Wang Yaoqi. Challenges and Prospects of Solid Waste Management in Ghana. International Journal of Environmental Monitoring and Analysis. Vol. 5, No. 4, 2017, pp. 96-102.

doi: $10.11648 /$ j.ijema.20170504.11

Received: April 25, 2017; Accepted: May 16, 2017; Published: July 6, 2017

\begin{abstract}
Urbanization is on the rise in Africa and this trend is expected to continue in the future. Of concern is that the infrastructure and land use planning including for waste management is not coping with the growth of urban areas (around 3.5\% annually, highest in the world). This is particularly urgent in the slum areas which constitute a big part of many of the cities and towns in Africa. Environmental sanitation and waste management is aimed at developing and maintaining a clean, safe, and pleasant physical and natural environment in all human settlements, to promote the socio-cultural, economic and physical well-being of all sections of the population. Waste management comprises a number of complimentary activities, the provision and maintenance of sanitary facilities, the provision of services, public education, regulation and legislation supported by clearly mandated institutions, adequate funding, research and development. This paper seeks to focus the challenges and prospects of solid waste management and the legal or policy arrangements available to ensure environmental sustainability.
\end{abstract}

Keywords: Solid Waste, Waste Management, Policy Framework, District Assembly, Ghana’s Waste Management, Land Fill

\section{Introduction}

Currently world cities generate about 1.3 billion tons of solid waste per year. This volume is expected to increase to 2.2 billion tones by 2025 . Waste generation rates will more than double over the next twenty years in lower income countries. Globally, solid waste management costs will increase from today's annual $\$ 205.4$ billion to about $\$ 375.5$ billion in 2025. Cost increases will be most severe in low income countries (more than 5-fold increases) and lower-middle income countries (more than 4-fold increases). [1] The global impacts of solid waste are growing fast. Solid waste is a large source of methane, a powerful GHG that is particularly impactful in the short-term. Locally, uncollected solid waste contributes to flooding, air pollution, and public health impacts such as respiratory ailments and cholera. In lower income country cities solid waste management is usually a city's single largest budgetary item. Improving solid waste management, especially in low income countries, is an urgent priority. Since May 1, 2015, humans have produced more than 9.4 billion tons of garbage. Nearly $30 \%$ remains to be processed. Waste generated in the world at present up to 1.9 billion tons, $70 \%$ of which is solid waste go into the landfill, only $19 \%$ are recycled, and $11 \%$ directly into the energy recycling.

Data show that Bahrain is the higher waste producer per capita, where on average every citizen produces $906.7 \mathrm{~kg}$ of solid waste per year, followed by the Comoros with a value of $813.3 \mathrm{~kg}$, the third is Canada, with an annual production per capita of 777 kilograms of solid waste. Kenyans make the least rubbish, with only $109.5 \mathrm{~kg}$ per capita solid waste. Ethiopia $(109.8 \mathrm{~kg})$ and Nepal $(115.7 \mathrm{~kg})$ production are also 
relatively small.

Events into the $21^{\text {st }}$ century indicate that waste in whatever form or classification have become a major consequence of modernization and economic development [2]. In the quest for development humanity did not budget for the problems related to the management of waste. As Ghana aspires to middle income status by 2020, a healthier and wealthier population will tend to generate more of all types of waste (domestic, commercial, industrial and hazardous). There is therefore need for urgent action based on a clear national strategy, plans and programmes to manage this trend.

Addressing poor attitude towards environmental management and environmental sanitation is critical to achieving any meaningful progress. Considering the emerging challenges of locating treatment and disposal sites, and based on experiences of developed economies, a desired long term outcome of improving environmental sanitation will take steps leading to an incremental reduction of the proportion of the waste stream that end up in final disposal, beginning with waste production prevention and reduction from all sources, especially at household level.

\section{The Concept of Solid Waste and Waste Management}

The term 'waste' has been defined differently by different people and authorities. Waste refers to an item, material or substance you as an individual consider useless at a given time and place [3].

The Environment Protection Act 1993, of the Environmental Protection Agency, define waste as any discarded, rejected, abandoned, unwanted or surplus matter whether or not intended for sale or for recycling, reprocessing, recovery or purification [4].

Waste is more easily recognised than defined. Something can become waste when it is no longer useful to the owner or fails to fulfil its purpose [5]. There are basically two types of waste namely liquid and solid waste. Solid waste comprises of all unwanted or discarded materials arising from both human and animal activities that have insufficient liquid content to be free flowing. Solid waste can also be defined as neither wastewater discharges nor atmospheric emissions, arising from domestic, commercial, industrial, and institutional activities in an urban area [6].

Some of the dominant types of solid waste include; municipal waste, green waste, construction and demolishing waste, medical waste, hazardous waste and electronic waste [3]. Most municipalities in Africa handle solid wastes from households, markets and institutions, street, public open spaces and non-hazardous waste from processing and industries. [7] These definitions holds true for the case of Ghana.

According to [8] the term municipal solid waste normally is assumed to include all of the waste generated in a community with the exception of industrial process waste and agricultural waste; sources as residential, commercial, institutional, construction and demolition, municipal services excluding treatment facilities, treatment plant sites; municipal incinerators.

In 2011, the World's total municipal solid waste was 250 million tonnes. It rose to 1.3 billion tonnes per year in 2012 , and was projected to reach 2.2 billion tonnes by the year 2025, with much of the increase coming from rapidly growing cities in developing countries [1].

Globally, wealthier regions generate higher quantities of solid waste than less wealthier ones, although some developing countries are among the top ten (10) Municipal Solid waste producing countries including Brazil, China, India and Mexico. For instance, members of the Organization for Economic Co-operation and Development (OECD), a group of 34 industrialized nations lead the world in Municipal Solid Waste generation, at nearly 1.6 million tonnes daily. By contrast, Sub-Saharan Africa produces less than one-eighth (1/8) as much (200,000 tonnes daily) [9].

Solid waste management refers to the 'collection, transportation, processing, recycling or disposal of waste materials' [3].

According to Mukisa, it ought to be appreciated that waste management practices differ for developed and developing countries, for urban and rural areas, and for residential and industrial producers. The volumes and types of waste in these different sources of waste justify the difference in the waste management practices". It therefore implies that the methods appropriate in one setting may not be in another setting. Hence, it is important to take into consideration the context of the waste source, in the determination of an appropriate solid waste management method.

The residents at certain locations, climatic conditions, and industrial activities are additional factors that have resulted in a significant variation in the volumes generated between locations of the world [6].

The volume of solid waste generated over the years has turned to increase with economic prosperity. Indeed, Volumes of solid waste have been trendy following and positively correlating with economic prosperity but inversely to the level of intervention on solid waste menace. Japan for instance exhibited such a trend between 1970s and the 1990s, a trend comparable to the United States over the past two decades. To the Japan Waste Management Association, "Japan solid waste quantities were rising until 1970, declined temporarily after the 1973 energy crisis, and then rose again slightly. As the economy prospered in the late 1980's, waste quantities increased sharply. However, "since 1990s generation rates have stabilized due economic slow-down and the implementation of waste reduction policies".

From the above, it is clear that generation rates may rise or fall. It is also noted that while some cities and regions may record higher volumes and faster rates of generation, others might not.

In Ghana, Accra generates nearly 900,000 metric tons of solid waste per year, "approximately $67 \%$ of which is organic. The rate of waste generation is approximately 0.5 kilograms per person per day [10]. Considering Ghana as a whole, an 
average of national daily generation per capita was $0.45 \mathrm{~kg}$ in 2005. [6]

Annually, Ghana generates about 3.0 million tonnes of solid waste [6] with a daily output of 13,000 tonnes of solid waste [11]. However, the national average per capita daily waste generation rates has increased to $0.5 \mathrm{~kg}$ currently [12]. Management of solid waste is the responsibility of the various Metropolitan Municipal and District Assemblies (MMDAs). These are the various decentralised government departments at the various regions of Ghana, and the problem of poor waste management cut across all the Assemblies. For example, in the Wa Municipality of the Upper West Region of Ghana, generates a total of 40.18 tonnes of municipal solid waste per day and the average solid waste generation per capita per day was estimated as $0.45 \mathrm{~kg}$ [6].

\section{Reasons for the Rise in Solid Waste Generation Volume}

Several reasons are attributed for the general rise in solid waste volumes and generation rates. However, the often-cited culprit is the economic growth and development. Economic prosperity has been historically associated with abundance in products and materials for consumption. Since economic growth is measured as a sustained increase in production output and expenditure, it is not a surprise to see that waste generation volume has increased along with economic growth in the past half-century [4]

Besides economic growth, high urban growth rates, population increases, and industrialization are the other notable factors. Rise in solid waste volumes in African and Asian countries like China is particularly caused by these factors. Rural urban migration or people moving from the peri urban centres to Accra-the capital city of Ghana has led to an increase in the generation rate of the city's waste stream.

Historical waste generation patterns of both developed and developing countries depicts that, both will have to deal with enormous quantities of urban waste with a changing composition in the years to come. [13]

By 2025, the high income countries are expected to generate about the same quantity of wastes, in terms of both mass and volume. Low income countries will be the largest generator of wastes on a mass basis, and will also surpass the total volume of waste produced by the high income countries. The increasing percentage of plastic and paper materials in the waste stream will contribute to the growing waste volume. [13]

\section{Approaches and Methods of Solid Waste Management}

Throughout most of history, the amount of waste generated by humans was insignificant due to low population density and low societal levels of the exploitation of natural resources. Common waste produced during pre-modern times was mainly organic and biodegradable waste, and these were released back into the ecosystem with minimum environmental impact.

The methods and approaches to solid waste management have evolved over the centuries. Reasons for such evolution generally have to do with the cost of usage of an approach, the convenience of usage of an approach, technology availability and environmental friendliness of the approach. It is worth noting that, over the period waste management and how it was approached until recently was reactive. Waste will be collected and disposed only when it has brought noticeably environmental damages. According to [14], the current waste management practice, which focuses on short-term impacts and end-of-pipe solutions, is reactive in nature and inadequate to promote sustainability within urban systems, across jurisdictions, and across generations. The developed world particularly the United States, took lead in engineering landfill sites, intensified recycling to cover wood waste and clothes. In US for instance, recycling and composting have received increasing application compared to decades ago. However, the national recycling rates experienced little growth in the past decade. In 2009, the latest data available indicated that $34 \%$ of $\mathrm{MSW}$ was recycled, compared to $29 \%$ in 2000 [14]. Based on the environmental impact assessment of each waste management method the U.S. EPA suggests a solid waste management hierarchy in which landfilling and incineration are the least preferred method, and source reduction and reuse are the most preferred method. In practice however, the least preferred methods of landfill disposal and energy recovery by combusting the waste have been the destination for $66 \%$ of the total waste stream in the U.S. [4].

Beside the above approaches, different experts are advocating for Integrated Solid Waste Management (ISWM) approach, though they each have different views as to the strategy for ISWM. The ISWM approach is based on the argument that solid waste menace is more than just a technical problem requiring a technical solution. ISWM distinguishes three important components in solid waste management and recycling systems. These are technological (technical) component, sustainability aspect (social, political, institutional, financial, economic and environmental aspects) and the stakeholder component. This means that solid waste can be managed effectively and efficiently by involving all the above components.

\subsection{Status of Solid Waste Management in Ghana}

In Ghana, waste management methods and approaches used include collection and deposing at landfill sites, which are mostly not engineered with the exception of few Metropolitan Assemblies which have engineered sanitary landfills. The remaining Assemblies in Ghana still resort to the crude open dump practice [12] In Accra for instance, collected waste is transported from Accra to a landfill in Tema, approximately 37 kilometres outside Accra [11]

Recycling, recovery and composting are methods that are also extensively advocated for but still minimally used even 
in the major cities of Accra, Kumasi and Tamale. The largescale Accra Composting and Recycling Plant which has recently put into operation can receive approximately 500 tons of municipal solid waste per day (organic and nonorganic). Scavengers and waste pickers mostly search through waste piles for metals plastics and other valuable recyclables.

Other approaches used include; burning, burying, indiscriminate disposal and reused. Burning, burying, indiscriminate disposal are not recommended approaches for managing solid waste. Unfortunately, these are rather the approaches intensively used today by individuals, businesses and even government institutions and waste management companies. Dumping solid waste into water bodies is common place, despite the dangers that it poses to aquatic life.

\subsection{Sustainable Waste Management Practices}

The most sustainable waste management practices are waste reduction and waste recycling as shown in Figure 1 below.

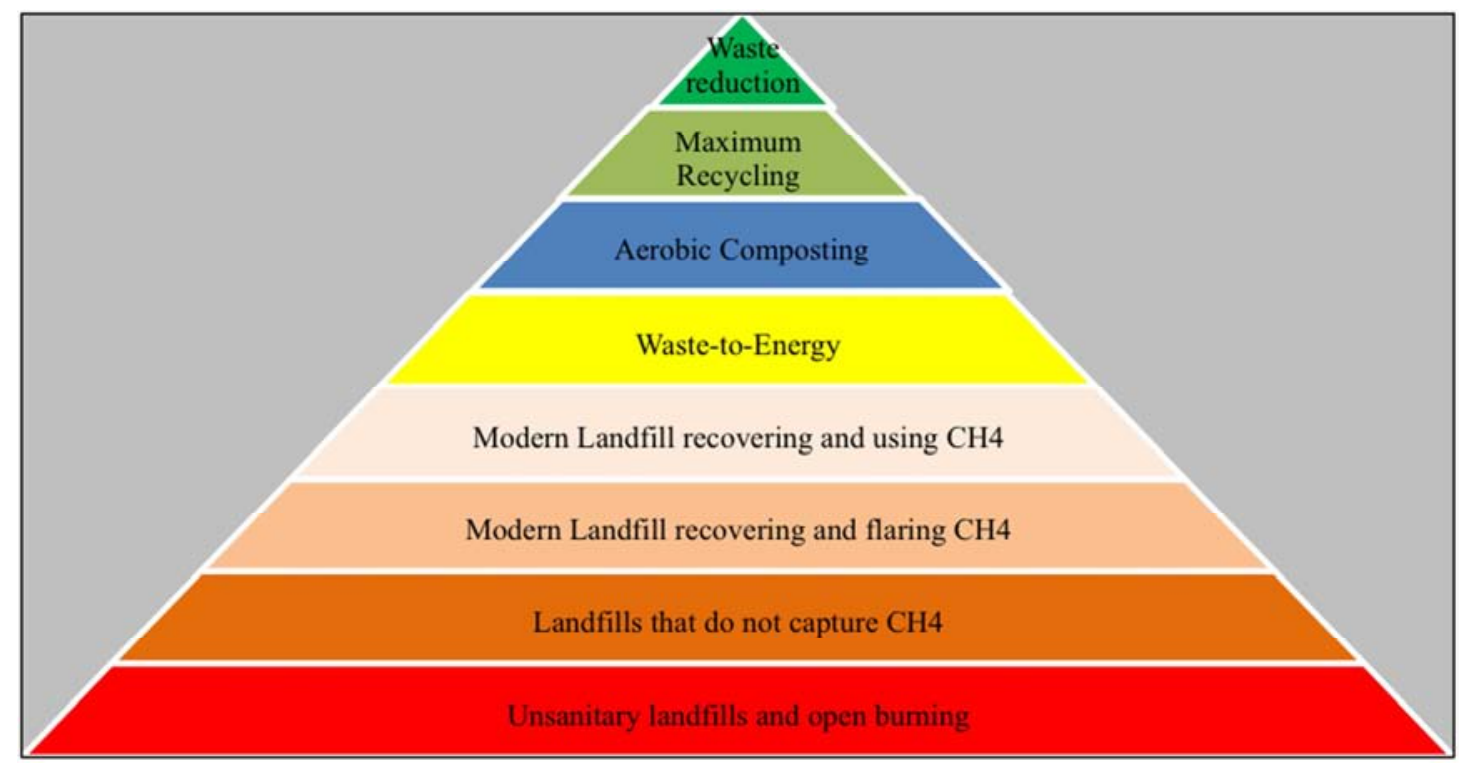

Figure 1. Hierarchy of sustainable waste management. Adapted from Rodriguez, 2011.

Effective waste recycling ultimately leads to waste reduction. It is possible to recycle completely a waste product only when the production and marketing processes themselves have integrated the target of $100 \%$ recycling as the ultimate goal of the design of the value chain, making it possible to generate money from the recycling activity itself (and allowing the recycling activity to not just be an end of chain cost).

In most African cities including Ghana, little is done and far little is happening currently in the areas of waste reduction and waste recycling as waste management practices. Waste management practices can be placed in the first and second rungs from the bottom of the hierarchy of sustainable waste management. Most companies that have taken into composting business initiatives have quit in many countries due to low patronage of such compost products. It is, however, flourishing in other countries such as Uganda and parts of South Africa [18].

\section{Policy and Institutional Framework for Solid Waste Management in Ghana}

General Waste Management in Ghana is the responsibility of the Ministry of Local Government and Rural Development, which supervises the decentralized
Metropolitan, Municipal and District Assemblies (MMDAs). However, regulatory authority is vested in the Environmental Protection Agency (EPA) under the auspices of the Ministry of Environment Science and Technology. The Metropolitan, Municipal and District Assemblies (MMDAs) are responsible for the collection and final disposal of solid waste through their Waste Management Departments (WMDs) and the Environmental Health and Sanitation Departments. The policy framework guiding the management of hazardous, solid and radio-active waste includes the Local Government Act (1994), Act 462, the Environmental Protection Agency Act (1994), Act 490, the Pesticides Control and Management Act (1996), Act 528, the Environmental Assessment Regulations 1999, (LI 1652) the Environmental Sanitation Policy of Ghana (1999), the Guidelines for the Development and Management of Landfills in Ghana, and the Guidelines for Bio-medical Waste (2000). All these Acts and Regulations emanate from the National Environmental Action Plan. At the MMDA level the Environmental Health and the Sanitation Departments take up issues of environmental sanitation including solid waste management. Periodically, clean up exercises are organized to encourage individual households maintain environmental sanitation. The Assemblies have the legal mandate to prosecute offenders for failure to maintain 
environmental hygiene.

\section{Challenges of Solid Waste Management in Ghana}

Globally, the main challenges to the effective management of solid waste is increasing volumes of waste due to faster rate of generation and the high cost of waste management. Solid waste management is an enormous problem for many city managers not only in Ghana but all over Africa, Asia, South America and even some European countries. "One to two-thirds of the solid waste generated are not collected. The truth is that prudent waste management processes are very costly whose short term returns are intangible. The financial outlay in waste management is high and it is difficult to raise the capital needed to manage the waste generated effectively and efficiently. The dilemma facing city administrators is how to raise the needed capital to finance waste management services in a sustainable manner" [12]

In addition to the above problems, Ghana is also beset with the challenge of modern technology which range from equipment and tools to the break-down of waste collection trucks and dustbins due to poor maintenance to inadequate skills required in tackling the solid waste menace. Such deficiencies have particularly hindered Ghana's ability to establish and operate engineered landfill sites, recycling and energy recovery plants. An investigation into the operations and management of solid waste dumped at the Kojokrom Dumpsite by the Sekondi-Takoradi Metropolitan Assembly (STMA), similarly noted that the permanent technical staff employed by the Assembly to manage the Kojokrom Dumpsite facility lack the requisite qualification [12]

Lack of proper planning for waste management services eventually leads to the inability of the authorities to predict and forecast the quantity of waste to be generated. Hence "the cyclical mantra of planning is thus invoked: planning to predict or predicting to plan". [15]

Besides Ghana as a whole lack sufficient engineered landfill sites for proper treatment and disposal of solid waste. The exception of the Metropolitan Assemblies which have engineered sanitary landfills the remaining Assemblies in Ghana still resort to the crude open dump practice. [12] Delay in the release of funds to MMDAs and the mandated private waste management partners, is yet another setback to solid waste management efforts in Ghana.

There is also the challenge of poor attitude of individuals in complementing the efforts of waste managing bodies. There are several instances were individual prefer lithering the environment with particularly plastic waste instead of using provided dustbins.

\section{Prospects of Effective Solid Waste Management in Ghana}

\subsection{Employment and Income Generation}

The increasing volume of waste contributed to the significant growth of the waste management industry. Zoom lion a private waste management company currently employs about 65,000 citizens out of labour force of Ghana. This improves the economic livelihood of these employees. Waste Management and Remediation Services is an economic sector that is formally identified in the U.S. Economic Census. The sector had 366,780 employees and generated over $\$ 73$ billion of revenue in 2007 [16]. Compared to a decade ago, the sector's employment has increased about $30 \%$, while the industry revenue has almost doubled. The sector has experienced much faster growth than the average growth rate of the national economy.

\subsection{Economies of Scale and Size in Waste Management}

Like many other industries, the waste industry experiences typical economies of scale. Prior to operation, initial investment in a waste processing or disposal facility typically involves a high fixed cost (e.g., for land purchase and facility construction) and capital compliance cost (e.g., for compliance determination, initial permission and monitoring). Waste facility operation cost, however, does not increase proportionately with waste disposal volume. The National Solid Waste Management Association estimated that the average unit cost of a typical municipal landfill declines by about $70 \%$ as its capacity increases from 250 to 3,000 tons per day. [17]

Given the economic characteristics discussed above, it is evident that merger activities can reduce the unit cost of waste management by taking advantage of existing infrastructure and equipment. Streamlined services may reduce the transaction costs along the service chain of waste collection, transportation, processing, and disposal

Local Governments should now be looking at waste as a business opportunity, to extract valuable resources contained within it that can still be used and to safely process and dispose wastes with a minimum impact on the environment. This means that the potential of privatizing waste management is very possible.

\subsection{Energy Generation from Waste}

Using waste to create energy is a viable option for most African cities. Waste can be incinerated to produce heat or electricity; and methane can be collected from landfills and be used to, again, generate heat or electricity.

There is high level of organic content of waste generated in most African cities. In Ghana, for example, about $66 \%$ of the total waste generated is organic, as shown in Figure 2 below. 


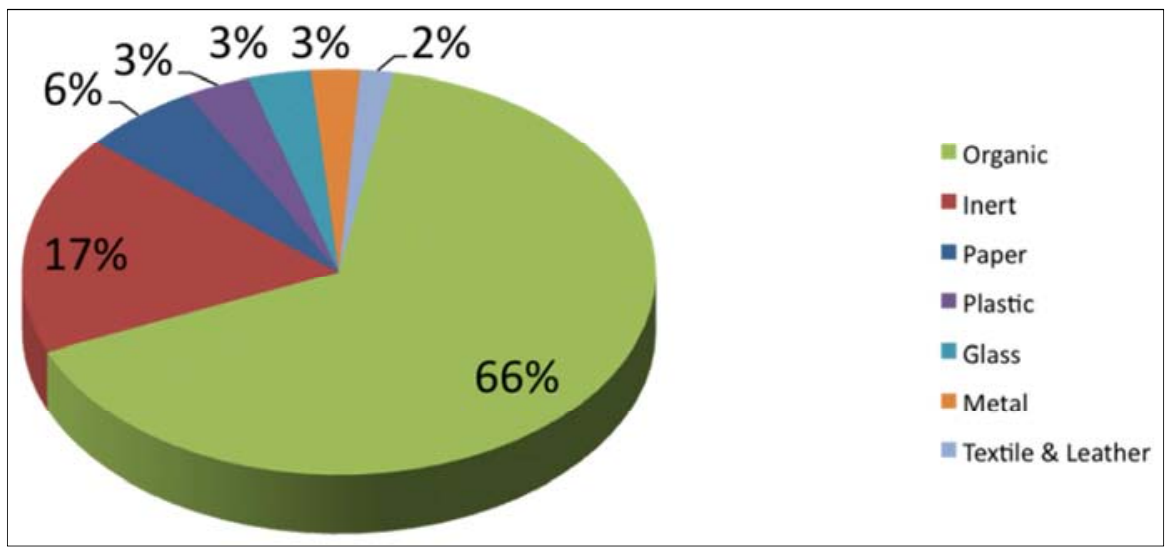

Figure 2. Waste type and composition in Ghana. Data sourced from Zoomlion Ghana Limited (2013).

Any organic waste from urban and rural areas as well as industries is a resource due to its ability to degrade and release methane, which can be used for energy generation. The problems caused by solid and liquid wastes can be significantly mitigated through the adoption of environmentally-friendly waste-to-energy technologies that will allow treatment and processing of wastes before their disposal.

Waste-to-energy is a win-win endeavour. As a sustainable waste management system it produces energy that can be sold for economic gains for the producer. It also provides green jobs. While it is thought that such projects are highly technical and often require imported skilled labour and technology from developed countries, local people, especially "waste scavengers," can be employed and use their skills. [18]

\section{Conclusion}

Solid waste collection and disposal are the critical issues in solid waste management. The various methods in disposing solid waste are sanitary landfills, composting, recycling, and incineration to produce energy. Integrated solid waste management is a complete waste production, collection, composting recycling and disposal system. An efficient ISWM system considers how to reduce, reuse, recycle, and manage waste to protect human health and the natural environment.

It involves evaluating local conditions and needs. Then choosing, mixing and applying the most suitable solid waste management activities according to the condition.

But in Ghana landfills are mainly used for final waste disposal. There is no integrated solid waste management plan at present. There are two main modes of solid waste collection system in Ghana namely door-to-door/house-to-house and communal container collection system. People still resort to unscrupulous methods of disposing solid waste such as dumping into gutters, drains, and road side among others which chock drainage pipes and leads to flooding during heavy rains. Solid waste management should be the primary responsibility of all but not only the management authorities or the government and District Assemblies. The provision of solid waste collection facilities, frequency of waste collection, and equipment for managing solid waste and the cost involved, which are the corner stone in managing solid waste, are the responsibility of the central government. However the management is challenged by factors such as inadequate funds to support waste management, inadequate equipment to support waste storage, collection and disposal, low collection coverage and irregular collection services. Other challenges include increasing volumes, lack of public participation in waste management, lack of proper planning and poor attitude among citizens.

\section{References}

[1] Bhada-Tata, D. H. (2012). A Global Review of Solid Waste Management. Washing DC: World Bank.

[2] Tsiboe, I. A. and Marbell, E. (2004). A Look at Urban Waste Disposal Problems in Accra. Roskilde University, Denmark.

[3] Mukisa P. K. (2009). Public Participation in Solid waste Management. A case of Kira town Councl; Uganda.

[4] US EPA (2009). Waste guidelines, EPA 842/0.

[5] Freduah, G. (2004). Problems of Solid Waste Management in Nima, Accra. University of Ghana, Legon.

[6] Puopiel F, (2010), Solid Waste Management in Ghana. The case of Tamale Metropolitan area.

[7] Achankeng E. (2003). Globalization, Urbanisation and Municipal Solid Waste management in Africa.

[8] Tchobanoglous, G., Theisen, H. and Vigil, S. (1993), Integrated Solid Waste Management. McGraw-Hill, Inc., NewYork.

[9] CalRecovery and UNEP (2005). Solid Waste management, volume II.

[10] Climate and Clean Air Coalition (2013). Solid Management in Accra.

[11] Foray J (2012), solid Waste Management in Ghana, a comprehensive case for West Africa pg. 4-11.

[12] Adu-Boahen A. (2012). Assessing the operation and management of the Kojokroom final waste disposal site by the Sekondi-Takoradi Municipal Assembly. 
[13] Hoornweg D. and Thomas, L. (1999). What a Waste: Solid Waste Management in Asia. Urban Development Division. The World Bank, Washington DC. USA.

[14] Ning Ai (2011). Challenges of sustainable Urban Planning: The case of Municipal Solid Waste management.

[15] Owusu-Sekyere, Harris, and Bonyah (2013). Forecasting and planning for Solid Waste generation in the Kumasi metropolitan Area of Ghana: An ARIMA Times Series.
[16] U. S. Department of Commerce. (2009). Economic-Wide Key Statistics: 1997-2007.

[17] National Solid Wastes Management Association (NSWMA). (2001). Competition in Owning and Operating Solid Waste Systems: Privatization Works Best.

[18] Innocent, A., Bawakyillenuo, S., \& Lemaire, X. (2015). Waste-to-energy: African cities can transform their energy landscapes. Accra: SAMSET. 